\title{
Photothermally triggered on-demand insulin release from reduced graphene oxide modified hydrogels
}

Authors: Florina Teodorescu ${ }^{\mathrm{a}}$, Yavuz Oz ${ }^{\mathrm{b}}$, Gurvan Quéniat ${ }^{\mathrm{a}}{ }^{\mathrm{c}}$, Amar Abderrahmani $^{\mathrm{c}}$, Catherine Foulon $^{\mathrm{d}}$, Marie Lecoeur ${ }^{\mathrm{d}}$, Rana Sanal ${ }^{\mathrm{b}}$, , Amitav Sanyal ${ }^{\mathrm{b}}$, Rabah Boukherrou ${ }^{\mathrm{b}},{ }^{\mathrm{a}}$, Sabine Szunerits ${ }^{\mathrm{a}}$

${ }^{a}$ Univ. Lille, CNRS, Centrale Lille, ISEN, Univ. Valenciennes, UMR 8520 - IEMN, F-59000 Lille, France

${ }^{\mathrm{b}}$ Department of Chemistry, Bogazici University, Bebek, 34342, Istanbul, Turkey

${ }^{\mathrm{c}}$ University Lille, CNRS, CHU Lille, Institut Pasteur de Lille, European Genomic Institute of Diabetes (EGID) FR 3508, UMR 8199, Genomique Intégrative et Modélisation des Maladies Métaboliques, F-59000 Lille, France

${ }^{\mathrm{d}}$ Univ. Lille, EA 7365 - GRITA-Groupe de Recherche sur les formes Injectables et les Technologies Associées, F-59000 Lille, France

${ }^{\mathrm{e}}$ RS Research, Teknopark Istanbul, Pendik, 34912, Istanbul, Turkey ${ }^{\mathrm{a}}$

First published: 27/10/2016

DOI: 10.1016/j.jconrel.2016.10.028

\begin{abstract}
.
On-demand delivery of therapeutics plays an essential role in simplifying and improving patient care. The high loading capacity of reduced graphene oxide (rGO) for drugs has made this matrix of particular interest for its hybridization with therapeutics. In this work, we describe the formulation of rGO impregnated poly(ethylene glycol) dimethacrylate based hydrogels (PEGDMA-rGO) and their efficient loading with insulin. Near-infrared (NIR) light induced heating of the PEGDMA-rGO hydrogels allows for highly efficient insulin release. Most importantly, we validate that the NIR irradiation of the hydrogel has no effect on the biological and metabolic activities of the released insulin. The ease of insulin loading/reloading makes this photothermally triggered release strategy of interest for diabetic patients. Additionally, the rGO-based protein releasing platform fabricated here can be expanded towards 'on demand' release of various other therapeutically relevant biomolecules.
\end{abstract}




\section{Graphical abstract.}

The table of contents entry: Poly(ethylene glycol) based hydrogels impregnated with rGO allow efficient loading and 'on demand' photothermal release of insulin while preserving its biological and metabolic activity.

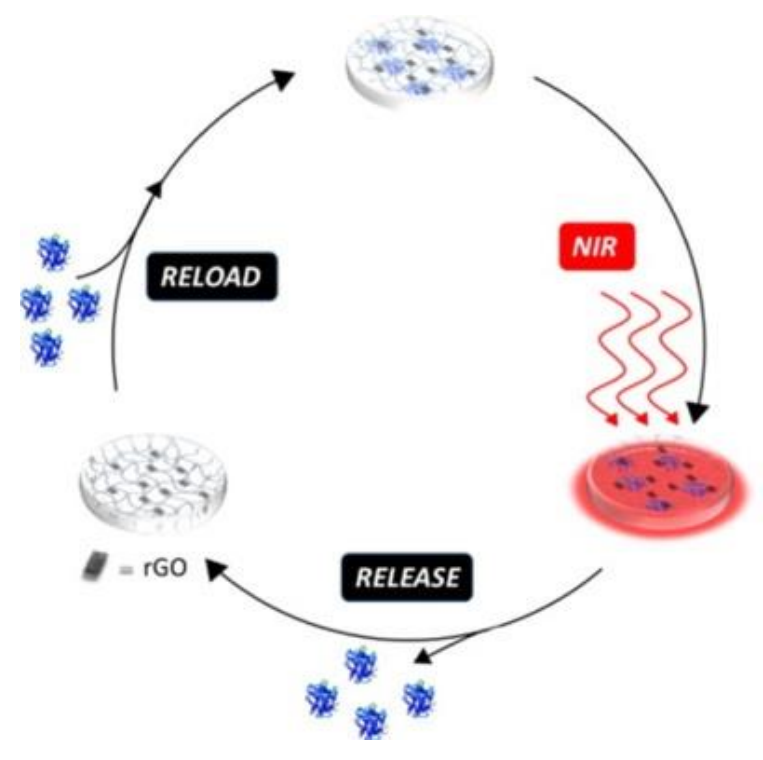

\section{Introduction}

The controlled release of active principles over long-term periods has been recognized as one of the most promising biomedical technologies for the treatment of certain types of diseases. Medical conditions such as cancer, diabetes and chronic pain require medications that must be dosed intermittently on demand and over a long period of time. To address these issues, intelligent drug delivery systems for on-demand release are highly desirable. These smart drug carriers offer important advantages over systematically administered drugs as they are able to overcome problems associated with drug solubility and stability and allow accumulation and release of the therapeutics at selected locations [1-6]. Among the different smart drug carriers such as liposomes, microspheres or hydrogels, graphene-based materials are emerging nanostructures for drug delivery [3,6-11]. The high specific surface area of graphene combined with the various interactions offered by this material ( $\pi$ - $\pi$ stacking, electrostatic, hydrophobic interactions, hydrogen bonding) are beneficial for achieving high drug loading of poorly soluble drugs without compromising potency or efficiency [6,12-14].

Graphene-based drug carriers have also successfully been utilized to develop stimuliresponsive nanocarriers $[3,15]$. The effectiveness of reduced graphene oxide (rGO) as a near infrared (NIR)-absorbing photothermal agent with excellent stability and rapid light-to-heat conversion under low-power NIR irradiation led to the development of photothermally 
triggered release systems [10,16-19]. Controlled release in response to illumination at a specific wavelength has the advantage of being non-invasive with the possibility of remote spatiotemporal control due to good heat confinement using optimized irradiation conditions [10]. Poly( $N$-isopropylacrylamide) functionalized graphene loaded with anticancer drugs has been previously exploited for temperature dependent drug release with reported higher potency and efficiency than the free drug [19]. FeCo-graphene nanocomposite showed remarkable enhanced photothermally triggered drug release [17]. Photothermally-induced cytosolic doxorubicin delivery via endosomal disruption as well as photothermally-controlled gene delivery from functionalized rGO was demonstrated recently by the group of Kim and co-workers [18]. Chitosan-modifed rGO loaded with doxorubicin was proposed by Wang et al. as thermosensitive nanogel, where upon near infrared (NIR) light action, rapid and repetitive doxorubicin release was observed [16]. Matteini et al. reported more recently the use of millisecond-long light pulses for the controlled release of different molecules from chitosan-modified rGO nanogels [10]. Using 8 repeated laser pulses of $200 \mathrm{~ms}$ and $40-$ $42 \mathrm{~J} \mathrm{~cm}^{-2}$ the delivery of insulin through the submicrometer pores of the chitosan-rGO film was demonstrated [10].

Indeed, the release of therapeutic proteins such as insulin is of high interest for treatment of diabetic patients. The oral administration of hydrophilic molecules such as insulin is encountered with many difficulties such as denaturation by the low $\mathrm{pH}$ of the gastric medium in the stomach as well as degradation by different digestive enzymes. Current treatment methods involve therefore regular injections of insulin, which can be both painful and inconvenient [20]. In order to overcome these hurdles, new insulin formulations as well as administration systems have been sought after. Kim et al. [21] developed sugar-responsive delivery vehicles of insulin based on polymersomes. Self-regulated insulin delivery was achieved by phenylboronic acid bearing hydrogels [22]. While electrically erodible polymer gels have been proposed by Kwon et al. [23], prolonged insulin delivery in diabetic rabbits was achieved using poly(lactide-ethylene-glycol) nanoparticles [24]. Insulin amidated pectin hydrogels were recently proposed as insulin delivery platforms by Hadebe et al. [25]. We have recently exploited the good electrical properties of rGO thin films for efficient electrochemical release of human insulin from rGO-modified electrodes [7]. Thermally modulated insulin release approaches have to be added to the list $[9,10,26]$. Poly $(N$ isopropylacrylamide-co-acrylic acid) microgel thin films [26] as well as polymeric microneedles [9] filled with insulin have been proposed as thermally activable delivery platforms.

Although desirable release profiles were obtained in these studies, extent of insulin loading and release 'on demand' still remains a challenge to enable translation of these findings into the clinic and thus warrants the development and testing of alternative platforms. Burst release of the therapeutics is often encountered in many polymer and hydrogel based formulations [10,27]. While the photothermal triggered release of insulin was demonstrated by Matteini [10], no details about loading/release capacity as well as on the insulin activity after photo-triggered release were given so far, crucial parameters when it comes to consider therapeutic applications.

In this paper, we provide an in-depth study and evolution of the insulin loading capacity into rGO entrapped poly(ethylene glycol) (PEG) hydrogels and laser-controlled, repetitive insulin release on demand. PEG-based hydrogels are investigated in this work as scaffold materials because they are widely utilized and are well established matrices for immobilization and 3

DOI: 10.1016/j.jconrel.2016.10.028- Journal: Journal of Controlled Release - Post-print 
encapsulation of biomolecules [8]. PEG molecules provide a non-interacting hydrophilic environment that preserves the biological activity of biomolecules by maintaining their structural conformation due to lack of denaturing interactions. Commercially available poly(ethylene glycol) dimethacrylate (PEGDMA) is utilized as hydrogel precursor and photopolymerized in the presence of varying amounts of well-dispersed rGO to yield hydrogels in a single step. The hydrogel matrix is designed to induce a photothermal heating effect upon exposure to near-infrared (NIR) irradiation, which results in a controlled release of insulin at therapeutic relevant concentrations in a few minutes. It will be shown that, upon optimization of the insulin loaded scaffold, therapeutic levels of insulin can be released in short time. Most importantly, we demonstrated that the photothermal triggered insulin release has no bearing on the biological activity of insulin, nor on cell viability a necessity required for effective therapeutic treatment. The ability of the hydrogel matrix for the transdermal delivery of insulin across the skin is in addition evaluated.

\section{Experimental section}

\subsection{Materials}

2-Hydroxy-4'-(2-hydroxyethoxy)-2-methylpropiophenone, human insulin, poly(ethylene glycol) dimethacrylate (PEGDMA, $\mathrm{M}_{\mathrm{n}}=550 \mathrm{gmol}^{-1}$ ), sodium hydroxide, acetic acid, hydrazine hydrate, and chitosan were purchased from Sigma Aldrich. PEGDMA was purified by passing through an activated aluminum oxide column prior to use. GO powder was purchased from Graphenia, Spain.

\subsection{Synthesis of PEGDMA-rGO hydrogels}

To $5 \mathrm{~mL} \mathrm{GO}$ aqueous suspension $(0.5 \mathrm{mg} / \mathrm{mL})$ was added hydrazine hydrate $(0.50 \mathrm{~mL}$, $32.1 \mathrm{mM}$ ) and heated in an oil bath at $100{ }^{\circ} \mathrm{C}$ for $24 \mathrm{~h}$ over which the reduced GO gradually precipitated out the solution. The product was isolated by filtration over a PVDF membrane with a $0.45 \mu \mathrm{m}$ pore size, washed copiously with water $(5 \times 20 \mathrm{~mL})$ and methanol $(5 \times 20 \mathrm{~mL})$, and dried over night in an oven.

For the preparation of PEGDMA-rGO hydrogels, $\mathrm{rGO}(0.1-1.2 \mathrm{mg})$ was dispersed in $130 \mu \mathrm{L}$ of water under ultrasonication. PEGDMA $(99.2 \mathrm{mg}, 0.18 \mathrm{mmol})$ and 2-hydroxy-4'hydroxyethoxy-2-methylpropiophenone $(0.4 \mathrm{mg}, 1.78 \mu \mathrm{mol})$ were added to the $\mathrm{rGO}$ dispersion and sonicated for 2 min to obtain a homogenous mixture. The mixture was irradiated using UV light $(365 \mathrm{~nm})$ for $15 \mathrm{~min}$. Thereafter, the rGO containing hydrogel was washed copiously with water, and incubated in water for $12 \mathrm{~h}$ to remove all unreacted reagents. The hydrogel was lyophilized before further characterizations. All the other PEGDMA-rGO hydrogels with varying rGO loadings were synthesized using similar procedure. 


\subsection{Insulin loading}

Insulin loading into the hydrogels was achieved by immersion in human insulin $(1 \mathrm{~mL}$, $100 \mu \mathrm{g} / \mathrm{mL}$ ) and shaking (150 rpm) at $4{ }^{\circ} \mathrm{C}$ overnight. The concentration of insulin loaded into the hydrogels was determined indirectly by measuring the absorption intensity of the remaining insulin in solution at $270 \mathrm{~nm}$ using UV-vis spectrometry. Standard human insulin calibration curve was generated beforehand from a series of insulin solutions ranging from 5 to $200 \mu \mathrm{g} / \mathrm{mL}$.

\subsection{Photothermal release studies}

Insulin release experiments were performed in $1 \mathrm{~mL}$ PBS $\left(\mathrm{pH} \mathrm{7.4)}\right.$ ) at $37^{\circ} \mathrm{C}$. The hydrogels were irradiated with a continuous mode laser (Gbox model, Fournier Medical Solution) with an output light at $980 \mathrm{~nm}$ at various power densities $\left(0.7-4 \mathrm{~W} \mathrm{~cm}^{-2}\right)$ for various time intervals (1-60 min). Thermal images were captured by an Infrared Camera (Thermovision A40) and treated using ThermaCam Researcher Pro 2.9 software. The quantity of insulin released was evaluated from the absorbance spectra of the solution collected after irradiation.

\subsection{Characterization}

SEM images were obtained by ESEM-FEG/EDAX Philips XL-30 (Philips, Eindhoven, The Netherlands) instrument using an accelerating voltage of $10 \mathrm{kV}$.; UV/Vis absorption spectra were recorded using SAFAS UV/Vis spectrophotometer in quartz cuvettes with an optical path of $10 \mathrm{~mm}$. The wavelength range was 200-1100 nm; Fourier transform infrared spectroscopy (FT-IR) analyses were performed on Thermo Fisher Scientific Inc, Nicolet 380. Micro-Raman spectroscopy measurements were performed on a LabRam HR Micro-Raman system (Horiba Jobin Yvon, France) combined with a 473-nm laser diode as excitation source. Visible light is focused by a $100 \times$ objective. The scattered light is collected by the same objective in backscattering configuration, dispersed by a $1800 \mathrm{~mm}$ focal length monochromator and detected by a CCD. Thermogravimetric analyses (TGA) were conducted on a TA instruments at a heating rate $10{ }^{\circ} \mathrm{C} / \mathrm{min}$ under a nitrogen atmosphere.

\subsection{Determination of insulin activity}

The activity of insulin released from the PEGDMA-rGO hydrogels (10 min, $980 \mathrm{~nm}$, $0.7 \mathrm{~W} \mathrm{~cm}^{-2}$ ) into water was evaluated, in vitro, on a human hepatic HepG2 cell line model using native insulin as a positive control and the same culture without insulin as a negative control. After overnight culture in a serum-free and glucose-free culture medium, HepG2 cells were incubated for $1 \mathrm{~h}$ without insulin (negative control), with native insulin (positive control) and with photothermally released insulin at a physiological active concentration of $200 \mathrm{nM}$. After $1 \mathrm{~h}$ of incubation, cells were lysed and proteins were collected. Expression of p-Akt and Akt proteins was evaluated by Western blotting analysis. For western blotting experiments, $40 \mu \mathrm{g}$ of total proteins of each condition were loaded and separated onto a polyacrylamide gel, then transferred on a nitrocellulose membrane. Immunoblotting for p-Akt and Akt was performed using anti p-Akt specific antibody (Thr-308, Cell signaling), anti Akt specific antibody (sc-8312, Santa Cruz) and fluorescence-coupled secondary antibodies against both mouse and rabbit primary antibodies. Analysis of the Western Blot was performed using Odyssey revelation process and ImageJ quantification technique. 


\subsection{Cytotoxicity assay}

Caco-2 human intestinal cells (Sigma-Aldrich, Steinheim, Germany) were cultured and maintained in Dulbecco's Modified Eagle's medium (DMEM, Gibco®) supplemented with $10 \%$ fetal bovine serum (FBS, Gibco ${ }^{\circledR}$ ) and $1 \%$ penicillin-streptomycin (Gibco $®$ ) in a humidified incubator at $37{ }^{\circ} \mathrm{C}$ and $5 \% \mathrm{CO}_{2}$. Cells were seeded at a density of $10^{4}$ cells/well in a 96-well plate and grown for $24 \mathrm{~h}$ before assay. The culture medium was replaced with a fresh medium and the hydrogels added. After $24 \mathrm{~h}$, the old medium was aspirated and cells were washed three times with PBS. The cell viability was evaluated using the Cell Counting Kit-8 (CCK-8, Sigma Aldrich) assay. Briefly, $10 \mu \mathrm{L}$ of the CCK-8 solution was added to each well containing $100 \mu \mathrm{L}$ of DMEM/10\% FBS and the plates were incubated for $3 \mathrm{~h}$ in an humidified incubator. The absorbance of each well was measured at $450 \mathrm{~nm}$ using a microplate reader (PHERAstar FS, BMG LABTECH GmbH, Germany). Each condition was replicated five times and the mean absorbance value of non-exposed cells was taken as $100 \%$ cellular viability.

\subsection{Apoptosis assay}

Apoptosis was determined by scoring cells displaying pyknotic nuclei (visualized with Hoechst 33,342). The counting was performed blind by three different experimenters.

\subsection{Skin staining and histology}

Before and after laser release studies porcine skin was cleaned in water, dissected and placed in paraformaldehyde ( $4 \% \mathrm{v} / \mathrm{v})$ for $24 \mathrm{~h}$ in order to fix the tissue. The samples were paraffined, sectioned and stained with the Masson's trichrome dye.

\subsection{Skin permeation experiments}

Skin permeation studies were performed using fresh porcine ear skin purchased in a local slaughterhouse. After thorough rinsing the pig ear with distilled water, the cartilage and the adipose tissue layer were removed with the aid of a surgical scalpel. The skin was gently shaved and cut into $1.8 \mathrm{~cm}^{2}$ circular pieces. After measurement of its thickness using a digimatic micrometer (Mitutoyo, France), the skin was used immediately thereafter for diffusion experiments.

Insulin skin diffusion experiments were carried out using static Franz diffusion cells (SES $\mathrm{GmbH}$, Analyse System, Bechenheim, Germany) exhibiting an effective area of $0.64 \mathrm{~cm}^{2}$. After filling the receptor compartment with degassed PBS $(1 \times, \mathrm{pH} 7.4)$, the solution was maintained at $32{ }^{\circ} \mathrm{C}$ and stirred with a magnetic stirring bar at around $500 \mathrm{rpm}$. The porcine skin was carefully clamped between the donor and the receptor compartment $(3.1 \mathrm{~mL})$ and pre-incubation in distilled water (receptor compartment medium) for $1 \mathrm{~h}$ before the insulinloaded hydrogel was applied to the skin previously wetted with $100 \mu \mathrm{L}$ of water to insure contact between the patch and the skin. The diffusion experiment was started and followed for $6 \mathrm{~h}$. The hydrogel was irradiated with a continuous wave laser at $980 \mathrm{~nm}$ for $10 \mathrm{~min}$ using $0.7 \mathrm{~W} \mathrm{~cm}^{-2}$. At determined time intervals, $250 \mu \mathrm{L}$ aliquots of diffused solution were removed from the receptor compartment and analysed by HPLC. After each sampling, an equal volume of fresh diffusion medium was added to the receptor compartment to maintain a constant 
volume. All experiments were performed in triplicates. The flux of insulin was determined according to Eq. (1):

$\mathrm{J}=\mathrm{A} / \mathrm{S}$

With

$J$

flux of insulin through the skin $\left(\mu \mathrm{g} \mathrm{cm}^{-2} \mathrm{~h}^{-1}\right)$

A

linear slope of the cumulative amount versus time curves in equilibrium conditions $\left(\mu \mathrm{g} \mathrm{h}^{-1}\right)$

$\mathrm{S}$

surface of the membrane of the Franz cell $\left(0.64 \mathrm{~cm}^{2}\right)$

HPLC analysis was performed as following:

Kinetex C18 (100 x 4.60 mm i.d., 2.6 um) column (Phenomenex, Le Pecq, France) preceded by a guard $\mathrm{C} 18$ column $(1 \times 4.60 \mathrm{~mm})$. Gradient elution mode at $1 \mathrm{~mL}$ min- 1 using $\mathrm{H} 2 \mathrm{O}(\mathrm{A})$ and acetonitrile (B), both containing $0.1 \%$ formic acid: linear increase in B from $20 \%$ to $90 \%$ in $5 \mathrm{~min} ; 25^{\circ} \mathrm{C}$; UV detection at $210 \mathrm{~nm}$.

\section{Results and discussion}

\subsection{Formulation of reduced graphene oxide (rGO) loaded poly(ethylene glycol) dimethacrylate hydrogels (PEGDMA-rGO)}

Reduced graphene oxide containing hydrogels (PEGDMA-rGO) were prepared through photopolymerization of an aqueous dispersion of $\mathrm{rGO}$, poly(ethylene glycol) dimethacrylate and a photo-initiator under UV irradiation at $365 \mathrm{~nm}$ (Fig. 1A). A free-standing and robust hydrogel was obtained and its chemical composition was confirmed using FT-IR spectroscopy (Fig. S1). The photographs of the hydrogel formulated in the absence and presence of rGO indicated further the successful integration of rGO, as the color-less PEGDMA hydrogel turned grey-black upon rGO loading (Fig. 1B). 
(A)
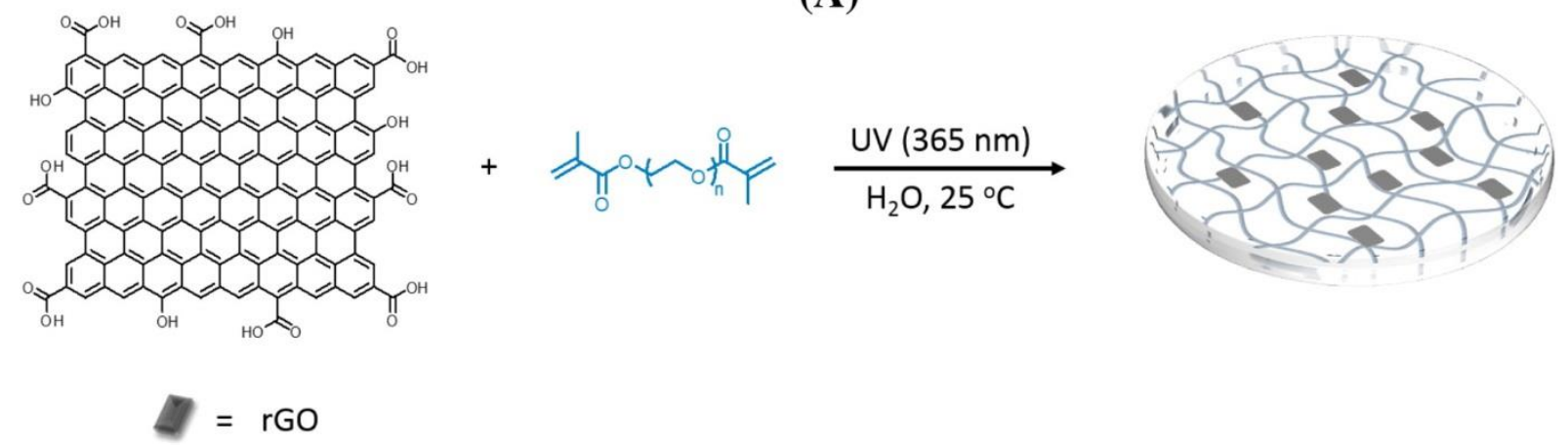

(B)

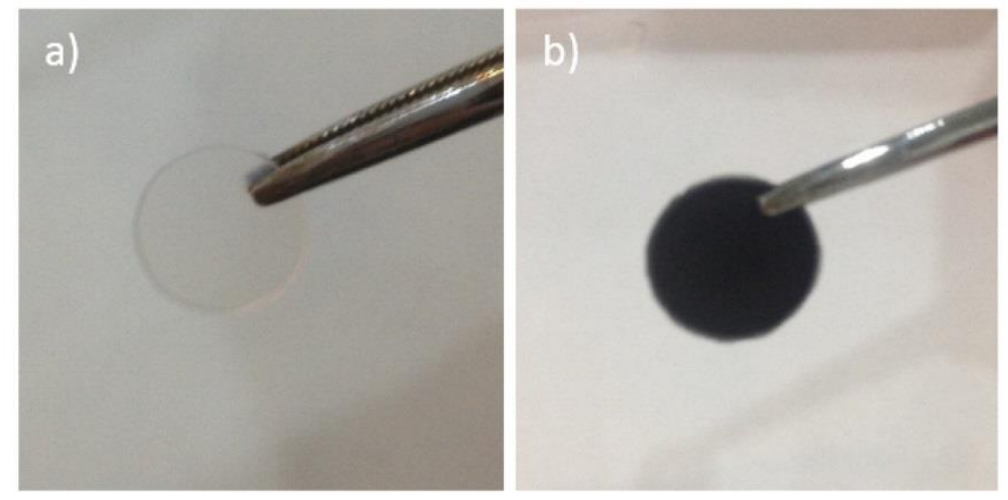

Fig. 1. (A) Illustration of the fabrication of PEGDMA-rGO hydrogels; (B) Photographs of free standing hydrogels without (a) and with $\mathrm{rGO}(0.8 \mathrm{mg})(\mathrm{b})$.

The rGO modified hydrogel was further characterized by UV-vis (Fig. 2A) spectrophotometry and Raman spectroscopy (Fig. 2B). The UV-vis spectrum of GO after reaction with hydrazine at $100{ }^{\circ} \mathrm{C}$ displayed an optical absorption peak at $273 \mathrm{~nm}$ with an absorption tail in the NIR characteristic of rGO (Fig. 2A). The PEGDMA hydrogel alone shows strong absorption between 206 and $280 \mathrm{~nm}$. The rGO loaded PEGDMA hydrogel shows a broad absorption in the UV-vis with a maximum at $273 \mathrm{~nm}$. The significant increase of the absorption tail in the NIR is in accordance of the integration of rGO into the PEGDMA hydrogels. 
(A)

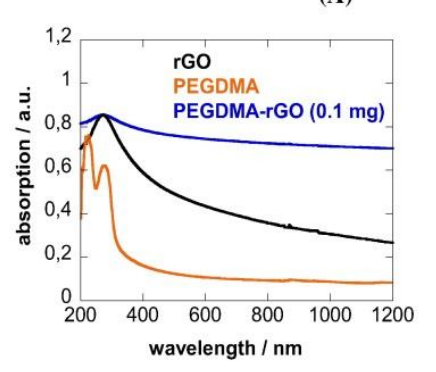

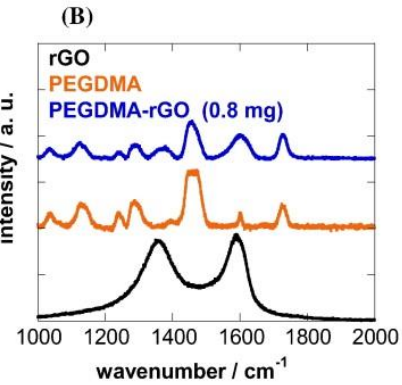

(C)
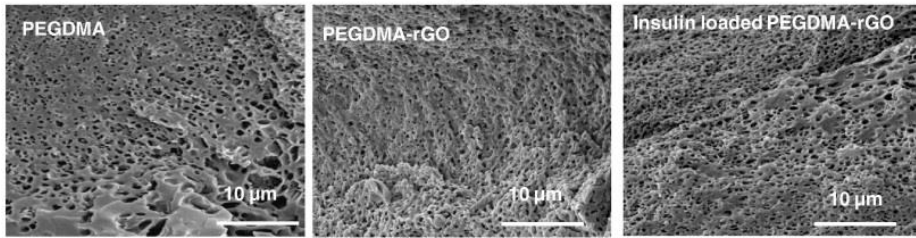

Fig. 2. Characterization of rGO and rGO loaded PEGDMA hydrogels: (A) UV-vis absorption spectra of rGO (black), PEGDMA (orange) and PEGDMA-rGO (0.1 mg, blue); (B) Raman spectra of rGO (black), PEGDMA (orange) and PEGDMA-rGO (0.8 mg, blue); (C) SEM images of PEGDMA, PEGDMA-rGO $(0.8 \mathrm{mg})$ and insulin loaded PEGDMA-rGO (0.8 mg).

The successful integration of rGO in to the hydrogel is validated by Raman spectroscopy. The Raman spectrum of rGO displays bands at $\approx 1350 \mathrm{~cm}^{-1}$ (D-band) and $\approx 1580 \mathrm{~cm}^{-1}$ (G-band) due to the local defects/disorder and the $\mathrm{sp}^{2}$ graphitized structure of $\mathrm{rGO}$, respectively (Fig. 2B). The $\mathrm{I}_{\mathrm{D}} / \mathrm{I}_{\mathrm{G}}$ intensity ratio was determined to be 0.93 for $\mathrm{rGO}$. The Raman spectrum of PEGDMA hydrogel exhibits several bands between 1000 and $1800 \mathrm{~cm}^{-1}$. The bands at $1728 \mathrm{~cm}^{-1}$ and $1032 \mathrm{~cm}^{-1}$ are assigned to $\mathrm{C}=\mathrm{O}$ and $\mathrm{C}-\mathrm{O}$ functions on PEGDMA respectively, while the bands at 1235 and $1285 \mathrm{~cm}^{-1}$ are due to $-\mathrm{CH}_{2}-$ bonds [28]. While the Raman signatures of the hydrogel prevail, the presence of rGO is clearly identified by the bands at 1359 and $1600 \mathrm{~cm}^{-1}$. The morphology of the PEGDMA-rGO was investigated using scanning electron microscopy (SEM), showing a homogenous microporous structure for lyophilized samples after immersion in liquid nitrogen before analysis (Fig. 2C).

\subsection{Insulin loading}

Insulin was integrated into PEGDMA-rGO hydrogels through simple immersion of the hydrogel into a human insulin solution $(100 \mu \mathrm{g} / \mathrm{mL})$ in water for $4 \mathrm{~h}$ at room temperature. The hydrogels possess limited swelling since the used PEG chains are short. These hydrogels absorb water equal to their weight as evidenced from the water uptake profile (see Supporting Material, Fig. S2). Loading the PEGDMA-rGO hydrogels with insulin did not alter the morphology of the patch as evidenced in Fig. $2 \mathrm{C}$ by comparison with the PEGDMA-rGO hydrogels before and after insulin loading.

The loading capacity of PEGDMA-rGO hydrogels for human insulin was evaluated by determining the concentration of insulin in solution before and after loading using UV-vis spectrometric measurements at $270 \mathrm{~nm}$. At this wavelength, insulin displays a characteristic absorption maximum (inset Fig. 3A), which scales linearly with its concentration in solution (Fig. 3A). As seen in Fig. 3B, insulin loading increases upon the increase of rGO in the hydrogel and saturates at $80 \%$ loading for hydrogels with rGO contents higher than $0.8 \mathrm{mg}$. 
These loadings are higher as compared to that obtained by mixing rGO $(1 \mathrm{mg} / \mathrm{mL})$ with human insulin $(0.1 \mathrm{mg} / \mathrm{mL})$ where a loading of $55 \%$ was reached [7]. The 3-D structure of the hydrogel seems to be favorable for the integration of insulin. Indeed, the major adsorption of insulin is due to interaction with the porous hydrophilic network of the PEG-based hydrogel network as suggested by Fig. 3B.

(A)

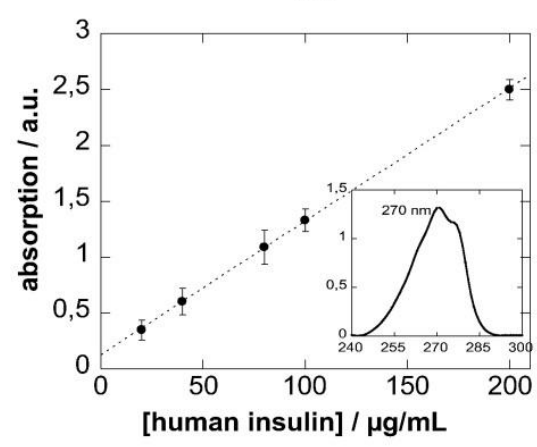

(C)

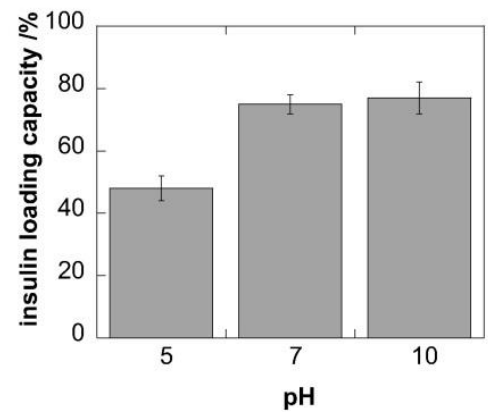

(B)

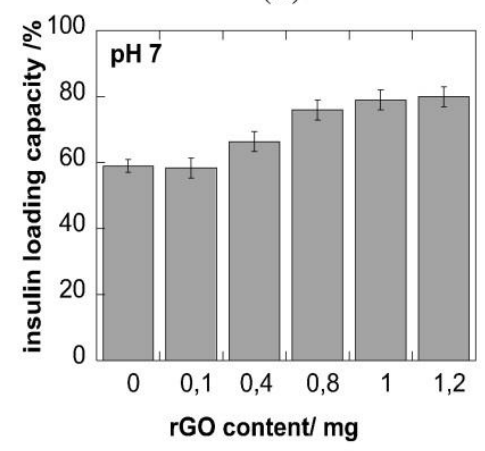

(D)

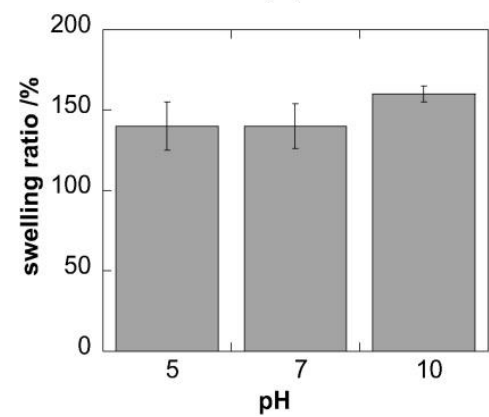

Fig. 3. Insulin loading of PEGDMA-rGO hydrogels: (A) Calibration curve used for the determination of loading capacity of PEGDMA-rGO hydrogels, inset: UV/Vis spectrum of human insulin solution; (B) Human insulin $(100 \mu \mathrm{g} / \mathrm{mL})$ loading capacity of PEGDMA-rGO as a function of $\mathrm{rGO}$ content at $\mathrm{pH} 7$; (C) Human insulin loading capacity of PEGDMA-rGO $(0.8 \mathrm{mg})$ hydrogel as a function of $\mathrm{pH}$ by adjusting the $\mathrm{pH}$ through the addition of $\mathrm{NaOH}$ or $\mathrm{HCl}$; (D) Swelling ratio of rGO-PEGDMA (0.8 $\mathrm{mg} \mathrm{rGO}$ ) hydrogels as a function of $\mathrm{pH}$ by adjusting the $\mathrm{pH}$ through the addition of $\mathrm{NaOH}$ or $\mathrm{HCl}$. The results are expressed as the mean \pm SEM of at least 5 independent samples for each group.

The loading capacity was found to be $\mathrm{pH}$ dependent, with a higher insulin loading at $\mathrm{pH}>7$ (Fig. 3C). This is in contrast to insulin loading onto GO where higher insulin loading was achieved at $\mathrm{pH}<5$, as below $\mathrm{pH} 5.4$ insulin is positively charged and interacts more strongly with the negatively charged GO [6]. This is also different from the case of rGO where no $\mathrm{pH}$ dependent loading was observed [7] as $\pi-\pi$ stacking interactions, being $\mathrm{pH}$ independent were believed to prevail between insulin and rGO. In addition, no significant influence of the $\mathrm{pH}$ on the swelling ratio of the hydrogel was observed (Fig. 3D). The increase in loading at $\mathrm{pH} 7$ is correlated with the better water solubility of insulin above $\mathrm{pH} 6$ [29]. Indeed, insulin is highly soluble at high and low $\mathrm{pH}$ conditions but is poorly dissolved at $\mathrm{pH} 5$ (near the $\mathrm{pKa}$ value of insulin). At $\mathrm{pH} 7$ the solubility of insulin is high enough to promote an effective diffusion through the gel resulting in increased loading capacity when compared to $\mathrm{pH} 5$ (Fig. $\underline{3 C})$. 


\subsection{Photothermal release of insulin}

The photothermal heating ability of PEGDMA and insulin loaded PEGDMA-rGO hydrogels was investigated under NIR irradiation (Fig. 4A). The size of the hydrogels used in these experiments was $1 \times 1 \mathrm{~cm}^{2}$ and had a thickness of approximately $1 \mathrm{~mm}$. As expected, PEGDMA hydrogels exhibit no photothermal heating ability even under high laser power. On the contrary, the rGO loaded PEGDMA hydrogels exhibited good photothermal properties. Using a laser power of $0.7 \mathrm{~W} \mathrm{~cm}^{-2}$, a temperature of $\approx 70^{\circ} \mathrm{C}$ can be achieved within $10 \mathrm{~min}$ for insulin loaded PEGDMA-rGO hydrogels with rGO loading of $0.8 \mathrm{mg}$ and higher (Fig. 4B). Such temperatures are believed to be high enough to interfere with the affinity between human insulin and rGO. Importantly, the hydrogels remained stable at this temperature since no thermal decomposition of the hydrogels was observed, as evidenced from the thermogravimetric analysis (see SI, Fig. S3). Additionally, no weight loss of hydrogel was observed upon such a photothermal irradiation in water. Under the same conditions, an equivalent amount of $\mathrm{rGO}(0.8 \mathrm{mg})$ drop-casted onto a glass interface reached a final temperature of only $60{ }^{\circ} \mathrm{C}$, which is $10^{\circ} \mathrm{C}$ lower than that recorded with PEGDMA-rGO hydrogel (Fig. 4B). The confinement of rGO into the hydrogel seems to have a positive effect on the photothermal properties of the matrix; temperatures around $100{ }^{\circ} \mathrm{C}$ can be even reached upon increasing the laser power to $4 \mathrm{~W} \mathrm{~cm}^{-2}$. The local confinement of the water molecules present within the hydrogel matrix in close proximity to the irradiated rGO allows effective localized temperature increase through slow heat dissipation into the surrounding medium.

(A)

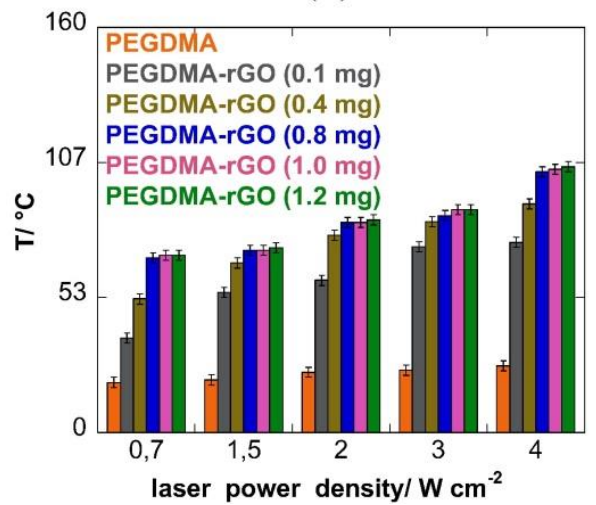

(B)

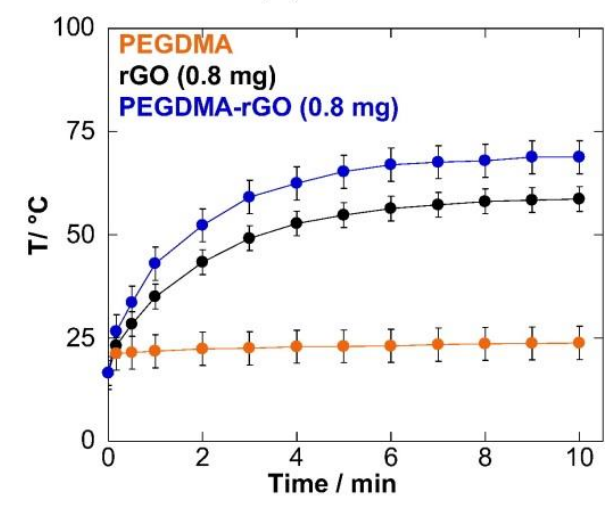

Fig. 4. (A) Change in solution temperature during illumination of different insulin loaded PEGDMA-rGO hydrogels at $980 \mathrm{~nm}$ for $10 \mathrm{~min}$ as a function of laser power; (B) Photothermal heating curves of rGO (black, $0.8 \mathrm{mg}$, drop casted onto glass), PEGDMA (orange), and PEGDMA-rGO $(0.8 \mathrm{mg})$ (blue) under NIR illumination $(980 \mathrm{~nm})$ at $0.7 \mathrm{~W} \mathrm{~cm}{ }^{-2}$ using a continuous wave laser. The results are expressed as the mean \pm SEM of at least 5 independent samples for each group.

Before determining the amount of insulin released during photothermal activation, the long term stability of the insulin impregnated PEGDMA-rGO hydrogels was established. The PEGDMA-rGO hydrogels with rGO loading of $0.8 \mathrm{mg}$ were used for the following experiments, as a further increase of $\mathrm{rGO}$ loading did not alter the photothermal characteristics of the hydrogel. 
Fig. 5A indicates that around $10 \%$ of insulin was desorbed from the hydrogel after 1 day when left immersed in PBS of $\mathrm{pH} 7$ at $37^{\circ} \mathrm{C}$. Thereafter, no further decrease was observed. This probably comes from a burst effect due to insulin present on the surface of the hydrogel.

(A)

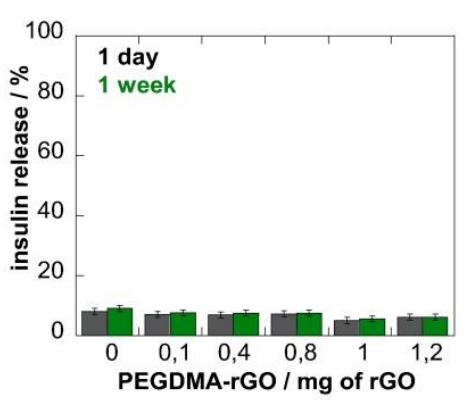

(B)

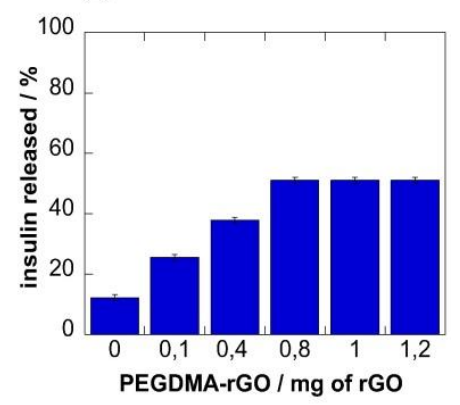

(C)

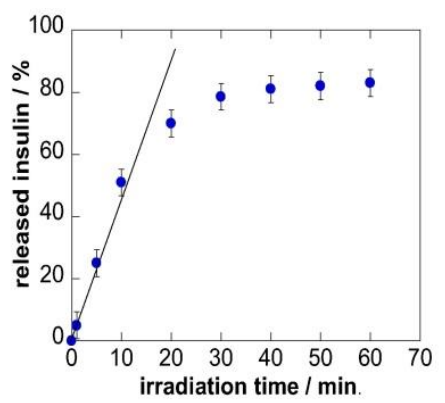

(D)

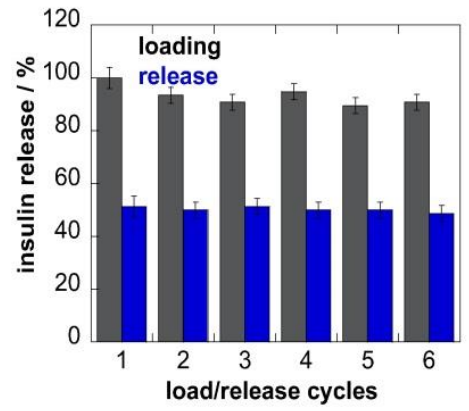

(E)

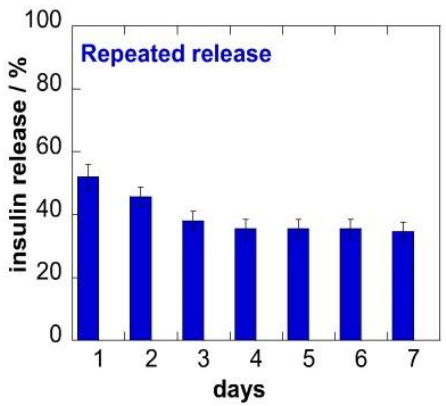

Fig. 5. Insulin release: (A) Stability of insulin loaded PEGDMA-rGO hydrogels in water for a period of 1 day (black) and one week (green); (B) Percentage of insulin released photothermally into water $\left(37^{\circ} \mathrm{C}\right)$ using a continuous wave laser at $980 \mathrm{~nm}, 0.7 \mathrm{~W} \mathrm{~cm}{ }^{-2}$ with illumination time of $10 \mathrm{~min}$; (C) Influence of irradiation time on insulin release $(980 \mathrm{~nm}$, $\left.0.7 \mathrm{~W} \mathrm{~cm}^{-2}\right)$; (D) Reloading and release of insulin on PEGDMA-rGO $(0.8 \mathrm{mg})$ hydrogels for 6 cycles; (E) Repeated insulin release over 7 days using 10 min laser illumination at $980 \mathrm{~nm}$, $0.7 \mathrm{~W} \mathrm{~cm}^{-2}$. The results are expressed as the mean \pm SEM of at least 5 independent samples for each group. 
Fig. 5B depicts the amount of photothermally released insulin upon illumination of the hydrogels at $980 \mathrm{~nm}$ for $10 \mathrm{~min}$ with a laser power of $0.7 \mathrm{~W} \mathrm{~cm}^{-2}$. In the absence of rGO in the PEGDMA hydrogel the insulin release was small, due to the inefficiency of the matrix to heat (Fig. 4A). The good heating capacity of PEGDMA-rGO patches with a rGO content of $>0.4 \mathrm{mg}$ results on the other hand on an efficient insulin release from the patch between 38 and $51 \%$ (corresponding to a solution concentrations reaching $6.5-8.7 \mu \mathrm{M}$ ). The photothermal triggered release is comparable to the electrochemical release of $\approx 7 \mu \mathrm{M}$ insulin [7]. To decrease diabetic blood glucose concentrations to normal levels, $250-330 \mathrm{nM}$ of insulin is needed [30]. The photothermal triggered release approach is thus well adapted for on-demand insulin release from the rGO loaded hydrogels. To investigate, if the system is working robustly, the influence of the irradiation time on the amount of insulin released was determined. Fig. $5 \mathrm{C}$ shows that for the first $10 \mathrm{~min}$ the release of insulin scales linearly with the irradiation time with a release rate of about $5 \%$ insulin per min. Thereafter, increase in irradiation time results in non linear insulin release, with a maximum $(\approx 80 \pm 3 \%)$ of released insulin after $40 \mathrm{~min}$.

An important feature of the hydrogels is their reusability. Reloading of insulin into the hydrogels where insulin was photothermally released could be performed with the same efficiency for six cycles (Fig. 5C), making these hydrogels of particular interest for the development of on-demand delivery platforms of diabetic patients. The insulin loaded PEGDMA-rGO hydrogels also provide sustained drug release upon NIR trigger. Fig. 5D shows the amount of insulin released from the hydrogel over a week when activated once a day for $10 \mathrm{~min}$ by laser illumination at $980 \mathrm{~nm}\left(0.7 \mathrm{~W} \mathrm{~cm}^{-2}\right)$. The insulin release is constant after 3 days with an insulin dose of $2.6 \mu \mathrm{g} / \mathrm{mL}$.

\subsection{Evaluation of photo-thermally release insulin activity}

To evaluate if the photothermal release of insulin from the PEGDMA-rGO hydrogels does not impact negatively the physiological and metabolic action of insulin, human hepatic HepG2 cells were cultivated in the presence of native or photothermally released insulin. Before this, we checked the potential toxicity of the patch itself and that of photo-released insulin in HepG2 cells. Cells viability was similar in cells cultured with different photo-released insulin preparations for $72 \mathrm{~h}$ (Fig. 6A). No toxicity was found in addition when cells were cultured with the different preparations at various times ( $1 \mathrm{~h}, 24 \mathrm{~h}$ or $48 \mathrm{~h})$. 
(A)

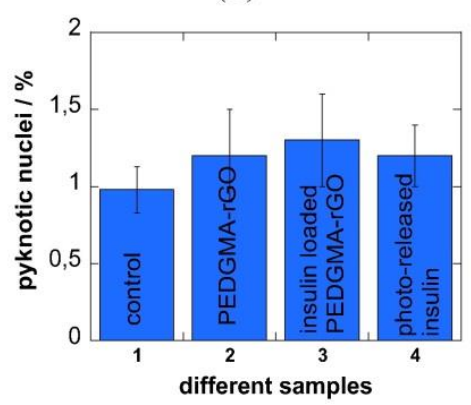

(B)

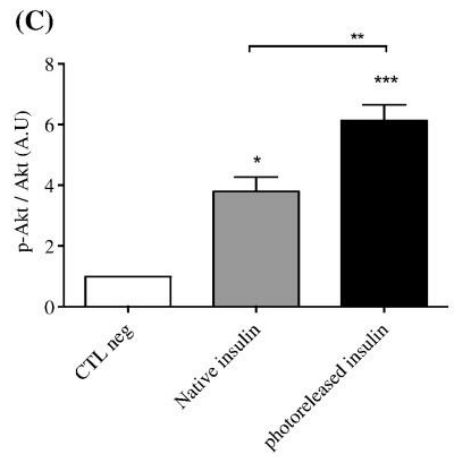

Fig. 6. (A) Effects of photo-released insulin on cell viability. Measurement of apoptotic HepG2 cells that were cultured for $72 \mathrm{~h}$ in the absence (control, 1) and presence of a PEGDMA-rGO hydrogel (2), insulin loaded PEGDMA-rGO hydrogel (3) and photo-released insulin (4). The fraction of cells undergoing apoptosis was determined by scoring the percentage of cells displaying pyknotic nuclei. Data are the mean of \pm SD; (B) Insulin activity from insulin loaded PEGDMA hydrogels determined on HepG2 cells Western blot of pAkt/Akt cell lysates from HEPG2 cells incubated under several conditions: without insulin, with native insulin or with photoreleased insulin (insulin loaded PEGDMA-rGO hydrogels); (C) Insulin activity shown by the ratio between p-Akt and Akt (A.U.) for all the samples in comparison to a negative control (CTL neg) (cells without insulin treatment). One-way ANOVA and multicomparisons test. The results are expressed as the mean \pm SEM of at least 3 independent samples for each group, $\left({ }^{*} \mathrm{p}<0.05\right.$, **p $<0.01$, ***p $\left.<0.001\right)$;

Insulin acts on HepG2 cells through its receptor, which after binding induces a signaling cascade leading to protein kinase B phosphorylation (p-Akt). This well-characterized key regulator of glucose metabolism in the liver will be used here as a marker for the determination of the metabolic activity of insulin. Fig. 6B indicates that the insulin activity (Akt phosphorylation, pAkt/Akt ratio) increased when HepG2 cells were treated with native insulin in comparison to non-treated cells (p-Akt/Akt ratio of 4.82 versus 1.0 for the negative control). A significant increase of Akt phosphorylation on HepG2 cells treated with the photothermally released insulin was observed (p-Akt/Akt ratio of 6.14 versus 1.0 for the negative control). It is important to notice that native insulin was less efficient to increase Akt phosphorylation than insulin released from the PEGDMA-rGO loaded hydrogels (p-Akt/Akt ratio of 6.14 versus 4.82 for cells treated with native insulin) (Fig. 6C). The reasons for this statistically greater activity in comparison to native insulin are currently unclear. However, it underlines insulin release under the used conditions has no negative effect on its activity. 


\subsection{Biocompatibility of photothermally activable PEGDMA-rGO hydrogels}

To demonstrate further the feasibility of the laser-activated hydrogel, the eventual photothermal damage to cells was investigated. As can be seen in Fig. 7A, the presence of the hydrogel did not induce any cytotoxicity to Caco-2 epithelial cells. Most importantly, the cell viability did not decrease even after illumination at $980 \mathrm{~nm}$ for $10 \mathrm{~min}$ at $0.7 \mathrm{~W} \mathrm{~cm}^{-2}$ pointing towards the absence of any photothermal damage to cells.

(A)

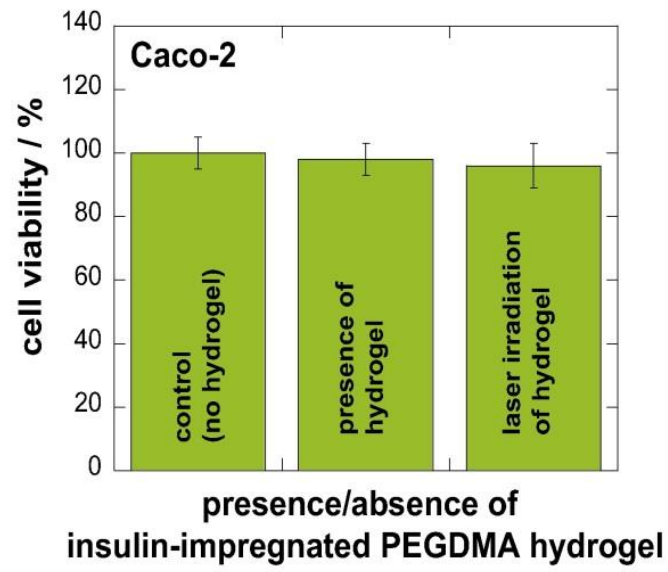

(B)
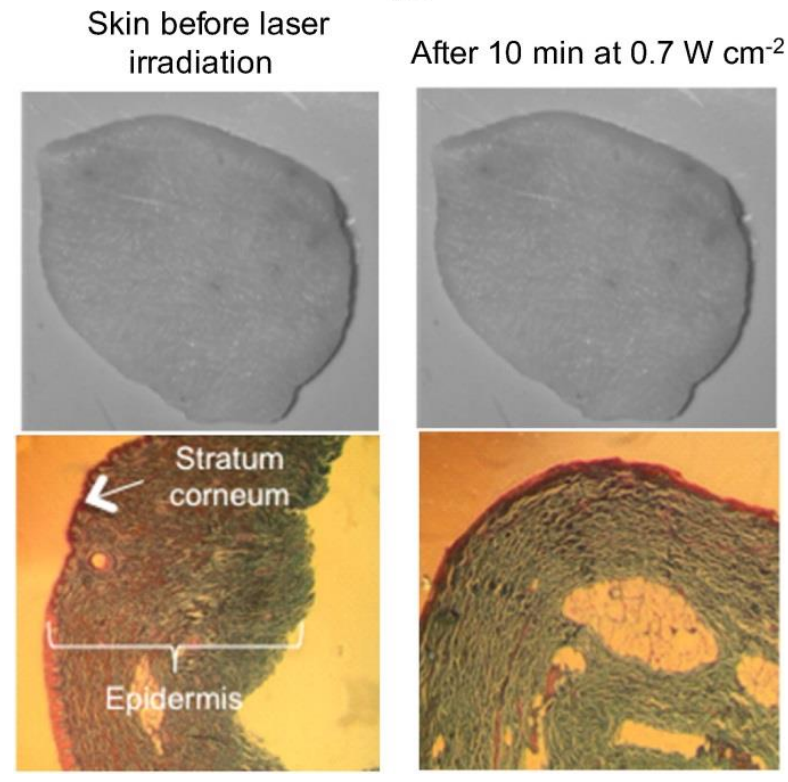

Fig. 7. (A) Relative cell viability of Caco-2 epithelial cell lines in the absence (control) and presence of insulin loaded PEGDMA-rGO hydrogels with and without laser illumination for $10 \mathrm{~min}$ at $980 \mathrm{~nm}$ at $0.7 \mathrm{~W} \mathrm{~cm}^{-2}$; (cell viability was evaluated using the CCK-8 assay, where the absorbance at $450 \mathrm{~nm}$ is measured using a microplate reader) without irradiation. The results are expressed as the mean \pm SEM of at least 3 independent samples for each group; (B) Representative photographs and histology of pig ear skin before and after treatment with a laser at $980 \mathrm{~nm}$ for $10 \mathrm{~min}$ with a laser power density of $0.7 \mathrm{~W} \mathrm{~cm}^{-2}$. 
The impact of the laser-irradiation on the skin structure was in addition taken into account by performing some histological investigations. Porcine ear skin was used since its stratum corneum is very similar to that of human stratum corneum[31]. The thickness of the skin was determined as being $1.6 \pm 0.4 \mathrm{~mm}$. Masson's trichrome dye was used for staining as keratin and muscle fibers are colored red, collagen and bone blue/green, cytoplasm red/pink, and cell nuclei brown/black. As seen in Fig. 7B, using a laser power density of $0.7 \mathrm{~W} \mathrm{~cm}^{-2}$ shows no histological changes. These results are encouraging for using the developed patch for transdermal insulin delivery.

\subsection{Transdermal insulin delivery through pig skin}

To determine the possibility of NIR laser heating of insulin impregnated PEGDMA-rGO hydrogels to delivery insulin transdermally, the transdermal flux of insulin through the skin was determined using a Franzen diffusion cell. Porcine ear skin of about $1.1 \pm 0.8 \mathrm{~mm}$ in thickness was used since its stratum corneum is believed to be very similar to that of human stratum corneum[31]. After wetting the insulin impregnated PEGDMA hydrogels to insure good contact with the skin, it was irradiated for $10 \mathrm{~min}$ at $980 \mathrm{~nm}$ at $0.7 \mathrm{~W} \mathrm{~cm}^{-2}$ and the passage of insulin through the skin was followed over $6 \mathrm{~h}$. Skin permeability was determined by measuring the transdermal flux of insulin using HPLC/UV (Fig. 8A), which allowed the detection of insulin as low as about $1 \mu \mathrm{g} \mathrm{mL}^{-1}$. Fig. $8 \mathrm{~B}$ represents the permeation profile of insulin across the skin. No passive insulin permeation is observed due to the high molecular weight of insulin, preventing insulin from penetrating intact skin. Irradiation at $0.7 \mathrm{~W} \mathrm{~cm}^{-2}$ resulted in a remarkable increase in the quantity of permeated insulin with a lag time of around $1 \mathrm{~h}$. This is comparable and even faster than the lag time reported by Prausnitz using ITC-labeled bovine insulin [32]. The increase in insulin permeation is believed to be correlated to the increase in temperature in the vicinity of the skin due to the photothermal heating effect of the PEGDMA-rGO hydrogel (Fig. 4A). At $0.7 \mathrm{~W} \mathrm{~cm}^{-2}$ irradiation, the insulin flux across the skin was estimated as $J=0.8 \pm 0.2 \mu \mathrm{g} \mathrm{cm}^{-2} \mathrm{~h}^{-1}$ for $3 \mathrm{~h}$. The skin permeability to insulin after laser irradiation using the PEGDMA-rGO hydrogels is significantly higher when compared to intact skin.

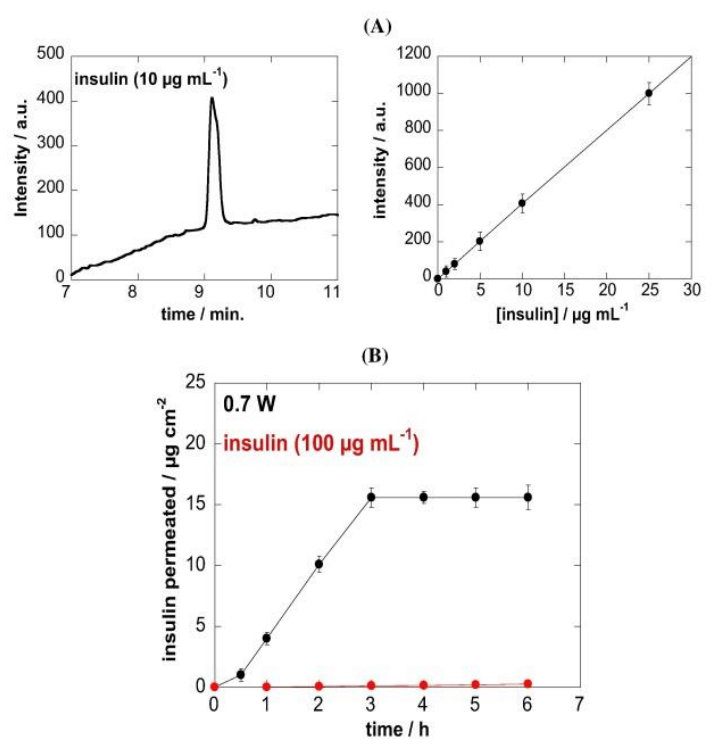


Fig. 8. (A) HPLC chromatogram of insulin $\left(10 \mu \mathrm{g} \mathrm{mL}^{-1}\right)$ and the corresponding calibration curve; (B) In vitro permeation profiles of insulin through porcine skin from insulin loaded PEGDMA-rGO hydrogels upon light irradiation at $980 \mathrm{~nm}$ for $10 \mathrm{~min}$ at $0.7 \mathrm{~W} \mathrm{~cm}^{-2}$

\title{
4. Conclusion
}

In conclusion, the potential of reduced graphene oxide impregnated poly(ethylene glycol) dimethacrylate hydrogels (PEGDMA-rGO) to act as an efficient carrier of therapeutic relevant quantities of insulin is demonstrated. We describe further the ability to deliver insulin in a controlled manner using laser-induced photothermal activation. It is based on the use of NIR laser irradiation at $980 \mathrm{~nm}$ with a laser power density of $0.7 \mathrm{~W} \mathrm{~cm}^{-2}$, which results in heating of the hydrogel and modulating the affinity of insulin in the PEGDMA-rGO hydrogel. We show for the first time, that the accounted temperature rise during the photothermal release does not have a negative consequence on the biological and metabolic activity of insulin as validated by an in vitro assay, and has no cytotoxic effect on cells. We further validated that the photothermal conditions used have no negative impact on the skin morphology with no skin inflammation being observed after insulin delivery.

Due to the ease of insulin loading and reloading as well as on the possibility to control the release kinetics by changing irradiation time and laser power, this insulin hydrogel should be of potential interest for the treatment of diabetic patients. The biocompatible nature of the rGO-PEGDMA hydrogels would allow its implantation under the skin of diabetic patients, where refilling of the hydrogel could be envisaged using microvalves as used already in insulin pumps. Moreover, the use of such an intrinsically soft martial such as rGO-PEGDMA enhances the possible integration of the patch with the human skin and its use as topical insulin patch. The possibility of such a strategy to deliver insulin through the skin has been validated by using porcine skin as a model. These first experiments, which are extremely encouraging, show that permeation of insulin is taking place in a relatively short time scale $(0-3 \mathrm{~h})$. Further studies in this direction are underway and will hopefully provide new opportunities for the treatment of diseases such as diabetes mellitus.

\section{Acknowledgements}

R.B. and S.S. gratefully acknowledge financial support from the Centre National de la Recherche Scientifique (CNRS), the University Lille1, the CPER "Photonics for Society, and the Nord Pas de Calais Region. S.S thanks the Institut Universitaire de France (IUF) for financial support. Support from the European Union through H2020-MSCA-RISE-2015 (No. 690836, PANG) is also acknowledged.

\section{Appendix A}

\section{Supporting Information}

\author{
Photothermally triggered insulin release from reduced graphene oxide loaded \\ poly(ethylene glycol)-based hydrogels
}


Florina Teodorescu, ${ }^{1}$ Yavuz Oz, ${ }^{2}$ Gurvan Quéniat, ${ }^{1,3}$ Amar Abderrahmani, ${ }^{3}$ Catherine Foulon, ${ }^{4}$ Marie Lecoeur, ${ }^{4}$ Rana Sanyal, ${ }^{2}$ Amitav Sanyal, ${ }^{2 *}$ Rabah Boukherroub ${ }^{1}$ and Sabine Szunerits ${ }^{*}$

[1] Dr. F. Teodorescu, Dr. G. Quéniat, Dr. R. Boukherroub, Prof. S. Szunerits

Univ. Lille, CNRS, Centrale Lille, ISEN, Univ. Valenciennes, UMR 8520 - IEMN, F-59000 Lille, France

[2] Y. Oz, Prof. R. Sanyal, Prof. A. Sanyal

Department of Chemistry, Bogazici University, Bebek 34342, Istanbul, Turkey

[3] Dr. G. Quéniat, Prof. A. Abderrahmani

University Lille, CNRS, CHU Lille, Institut Pasteur de Lille, European Genomic Institute of Diabetes (EGID) FR 3508, UMR 8199, Genomique Intégrative et Modélisation des Maladies Métaboliques, F-59000 Lille, France

[4] Dr. C. Foulon, Dr. M. Lecoeur

University Lille, EA 7365 - GRITA-Groupe de Recherche sur les formes Injectables et les Technologies Associées, F-59000 Lille, France.

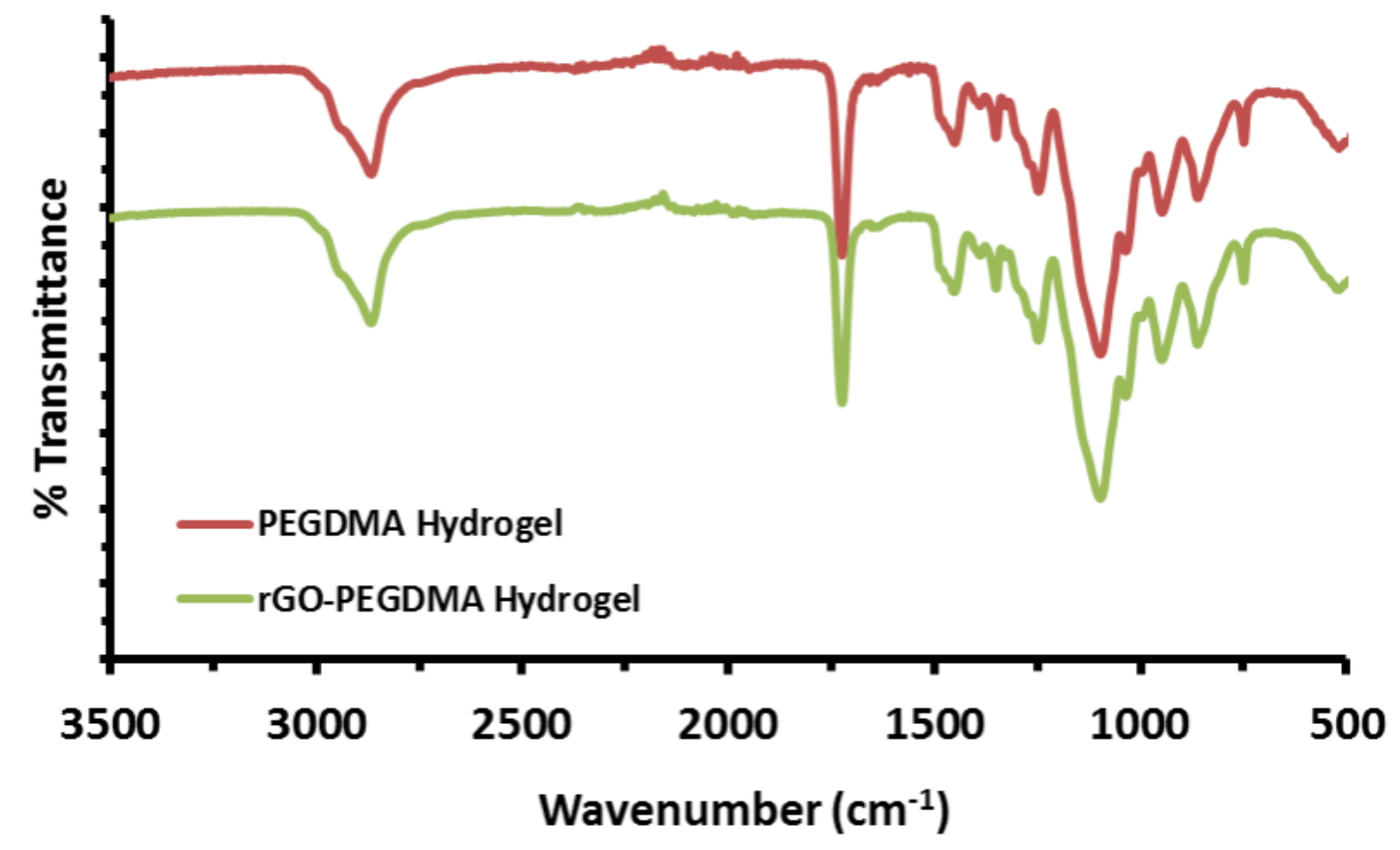

Figure S1. FT-IR spectra of PEGDMA (red) and rGO-PEGDMA (green) hydrogels. 


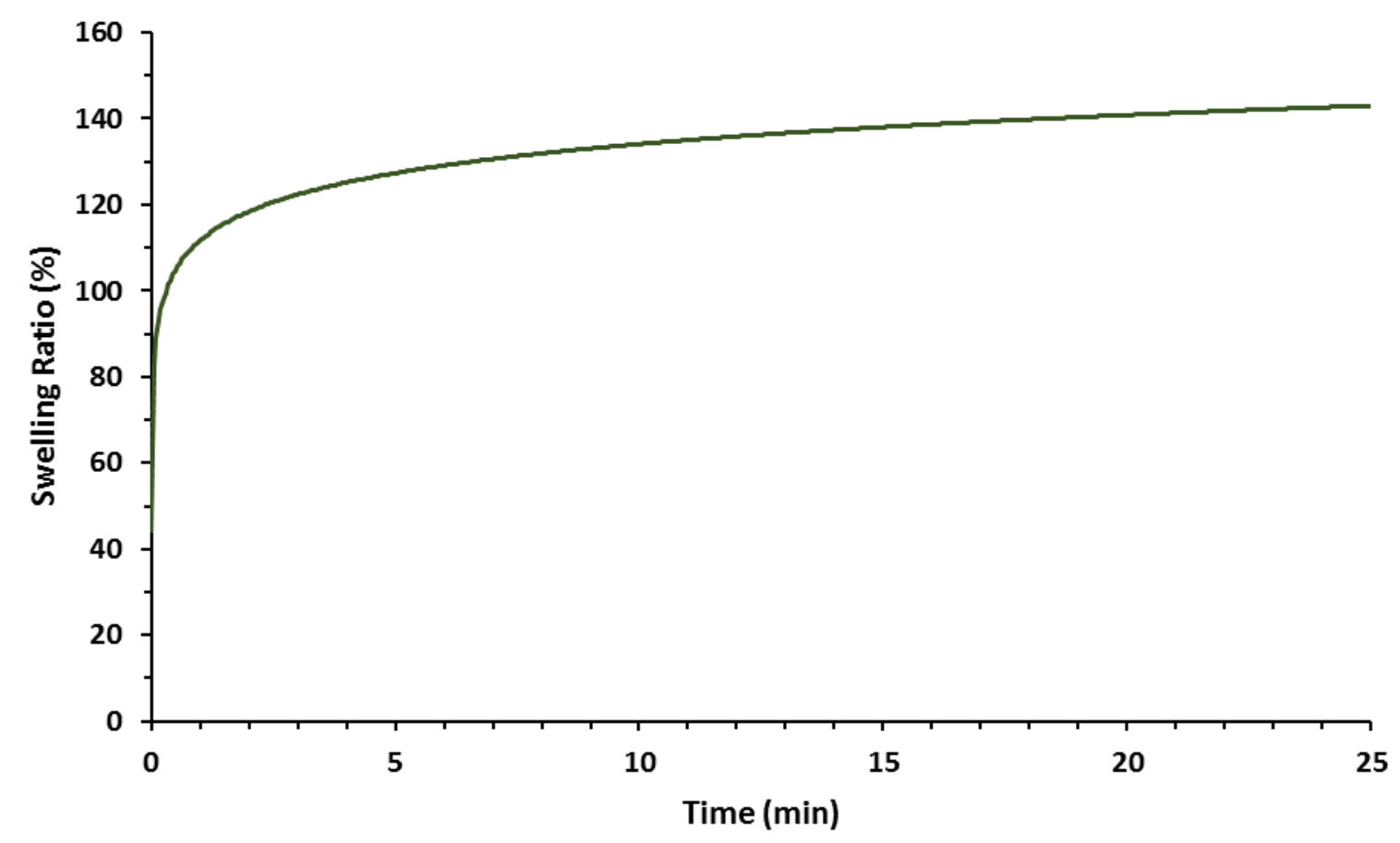

Figure S2. Water uptake profile of rGO-PEGDMA hydrogel at pH 7.0.

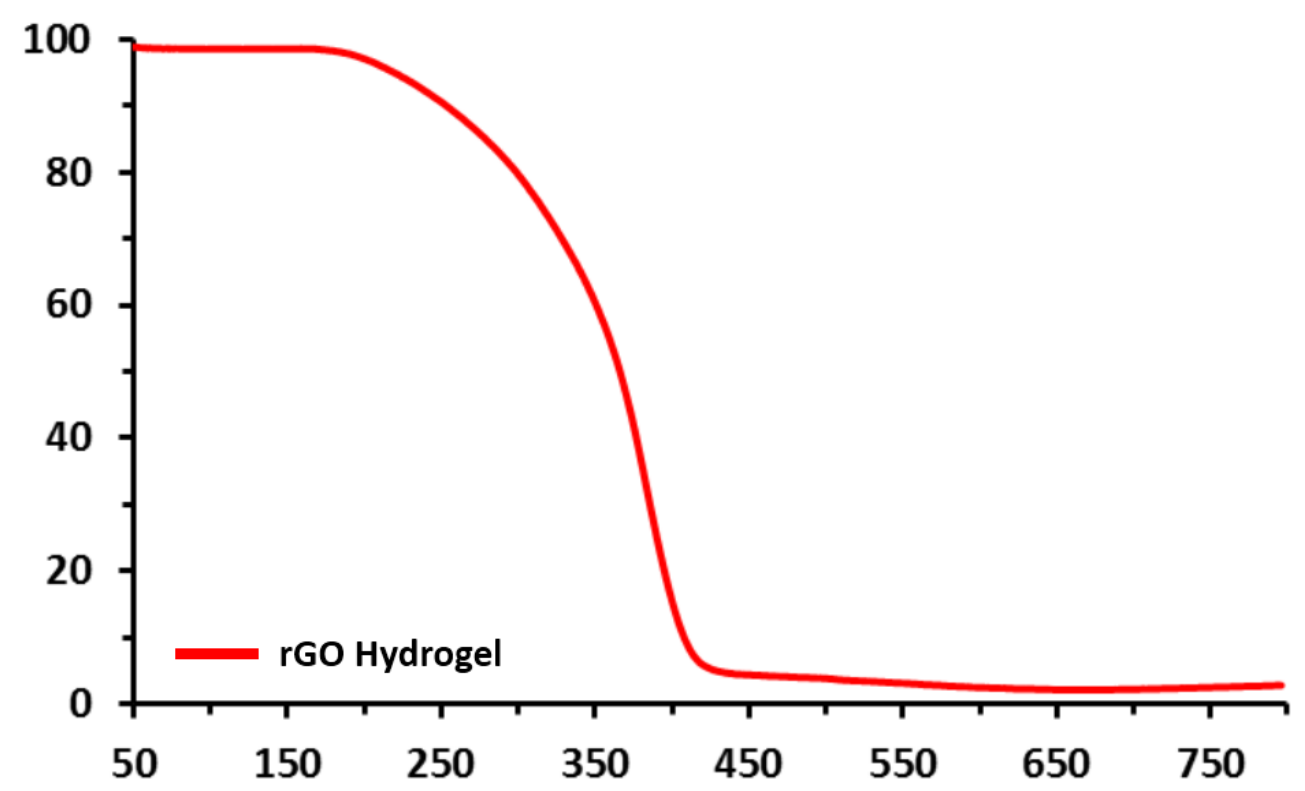

Figure S3. TGA curve of PEGDMA-rGO $(0.8 \mathrm{mg})$ based hydrogel.

19

DOI: 10.1016/j.jconrel.2016.10.028- Journal: Journal of Controlled Release - Post-print 


\section{Experimental condition for chromatography (Figure 8):}

Kinetex C18 (100 x 4.60 mm i.d., 2.6 um) column (Phenomenex, Le Pecq, France) preceded by a guard C18 column $(1 \times 4.60 \mathrm{~mm})$ was used. Gradient elution mode at $1 \mathrm{~mL}$ min-1 using $\mathrm{H}_{2} \mathrm{O}$ (A) and acetonitrile (B), both containing $0.1 \%$ formic acid: linear increase in B from 20 $\%$ to $90 \%$ in $5 \mathrm{~min} ; 25^{\circ} \mathrm{C}$; UV detection at $210 \mathrm{~nm}$ was used.

FT-IR spectra of PEGDMA and rGO-PEGDMA hydrogels (Figure S1); Water uptake profile of rGO-PEGDMA hydrogel at pH 7.0 (Figure S2); TGA curve of PEGDMA-rGO (0.8 mg) based hydrogel (Figure S3) and HPLC analysis conditions.

\section{References}

1)J. Kost, R. Langer

Responsive polymeric delivery systems

Adv. Drug Deliv. Rev., 64 (2012), pp. 327-341

2) H. Li, Y. Yu, S.F. Dana, B. Li, C.-Y. Lee, L. Kang

Novel enginerred systems for oral, mucosal and transdermal drug delivery

J. Drug Target. (2013), pp. 1-19

3) S. Goenka, V. Sant, S. Sant

Graphene-based nanomaterial for drug delivery and tissue engineering

J. Control. Release, 173 (2014), pp. 75-88

4) A.P. Blum, J.K. Kammeyer, A.M. Rush, C.E. Callmann, M.E. Hahn, N.C. Gianneschi Stimuli-responsive nanomaterials for biomedical applications

J. Am. Chem. Soc., 137 (2014), pp. 2140-2154

5) S. Mura, J. Nicolas, P. Couvreur

Stimuli-responsice nanocarriers for drug delivery

Nat. Mater., 12 (2013), pp. 991-1003

6) K. Turcheniuk, A. Mororina, P. Subramanian, A. Barras, V. Zaitsev, V. Kuncser, A. Leca, A. Martoriati, K. Cailliau, J.-F. Bodart, R. Boukherroub, S. Szunerits

Insulin loaded iron magnetic nanoparticles-graphene oxide composites: synthesis, characterization and application for diabetes treatment

RSC Adv., 4 (2014), pp. 865-875

7) F. Teodorescu, L. Rolland, V. Ramarao, A. Abderrahmani, D. Mandler, R. Boukherroub, S. Szunerits

Electrochemically triggered release of human insulin from an insulin-impregnated reduced graphene oxide modified electrode

Chem. Commun., 51 (2015), pp. 14167-14170

8) N.M. Kenna, P. Calvert, A. Morrin, G.G. Wallace, S.E. Moulton

Electro-stimulated release from a reduced grpahene oxide composite hydrogel

J. Mater. Chem. B, 3 (2015), p. 2530

DOI: 10.1016/j.jconrel.2016.10.028- Journal: Journal of Controlled Release - Post-print 
9) H. Lee, T.K. Choi, Y.B. Lee, H.R. Cho, R. Ghaffari, L. Wang, H.J. Choi, T.D. Chung, N. Lu, T. Hyeon, S.H. Choi, D.-H. Kim

A graphene-base electrocehmical device with thermoresponsice microneedles for diabetes monitoring and therapy

Nat. Nanotechnol. (2016)

10) P. Matteini, F. Tatini, L. Cavigili, S. Ottaviano, G. Ghini, R. Pini

Graphene as a photothermal switch for controlled drug release

Nanoscale, 6 (2014), p. 7947

11) J. Hong, N.J. Shah, A.C. Drake, P.C. DeMurth, J.B. Lee, J. Chen, P.T. Hammond

Graphene mulilayers as gates for multi-week sequential release of proteins from surfaces

ACSNano, 6 (2012), pp. 81-88

12) S. Park, J. An, R.D. Jung, S.J. Piner, X. An, A. Li, A. Velamakanni, R.S. Ruoff

Colloidal suspensions of highly reduced graphene oxide in a wide variety of organic solvents

Nano Lett., 9 (2009), pp. 1593-1597

13) Y. Xu, Q. Wu, Y. Sun, H. Bai, G. Shi

Three-dimensional self-assembly of graphene oxide and DNA into multifunctional hydrogels

ACS Nano, 4 (2010), pp. 7358-7362

14) Z. Liu, J.T. Robinson, X. Sun, H. Dai

PEGylated nanographene oxide for delivery of water-insoluble cancer drugs

J. Am. Chem. Soc., 130 (2008), pp. 10876-10877

15) J. Zhang, L. Song, Z. Zhang, N. Chen, L. Qu

Environmentally responsive graphene systems

Small, 10 (2014), pp. 2151-2164

16) C. Wang, J. Mallela, U.S. Garapati, S. Ravi, V. Chinnasamy, Y. Girard, M. Howell, S. Mohapatra

A chitosan-modified graphene nanogel for noninvasice controlled drug release

Nanomedicine, 9 (2013), pp. 903-911

17) S.P. Sherlock, S.M. Tabakman, L. Xie, H. Dai

Photothermally enhanced drug delivery by ultra-small multifunctional FeCo/graphiticshell nanocrystals

ACS Nano, 5 (2011), pp. 1505-1512 
18) H. Kim, D. Duhwan Lee, J. Kim, T.-I. Kim, W.J. Kim

Photothermally triggered cytosolic drug delivery via endosome disruption using a functionalized reduced graphene oxide

ACS Nano, 7 (2013), pp. 6735-6746

19) Y. Pan, H. Bao, N.G. Sahoo, T. Wu, L. Li

Water-soluble poly( $N$-isopropylacrylamide)-graphene sheets synthesized via click chemistry for drug delivery

Adv. Funct. Mater., 21 (2011), pp. 2754-2763

20) M. Buysschaert, A.E. Lambert

The insulin pen

Lancet, 333 (1989), p. 965

21) H. Kim, Y.J. Kang, S. Kang, K.T. Kim

Monosaccharide-responsive release of insulin from polymersomes of polyboroxole block copolymers at neutral pH

J. Am. Chem. Soc., 134 (2012), p. 4030

22) Matsumoto, T. Ishii, J. Nishida, H. Matsumoto, K. Kataoka, Y. Miyahara

A synthetic approach toward a self-regulated insulin delivery system

Angew. Chem. Int. Ed., 124 (2012), pp. 2166-2170

23) I.C. Kwon, Y.H. Bae, S.W. Kim

Electrically erodibel polymer gel for controlled release of drugs

Nature, 354 (1991), pp. 291-293

24) L. Tomar, C. Tyagi, M. Kumar, P. Kumar, H. Sing, E. Choonara, V. Play

In vivo evaluation of a conjugated poly(lactide-ethylene glycol) nanoparticle depot formulation for prolonged insulin delivery in the diabetic rabbit model

Int. J. Nanomedicine, 8 (2013), pp. 507-520

25) S.I. Hadebe, P.S. Nhubane, M.R. Serumula, C.T. Musabayane

Transdermal delivery of insulin by amidated pectin hydrogel matrix patch in streptozotocin-induced diabetic rats: effects on some selected metabolic parameters

PLoS One, 9 (2014), Article e1014461

26) C.M. Nolan, M.J. Serpe, A.L. Lyon

Thermally modulated insulin release from microgel thin films

Biomacromolecules, 5 (2004), pp. 1940-1946

27) U.G. Spizzirri, M. Curcio, G. Cirillo, T. Spataro, O. Vittoria, N. Picci, S. Hampel, F. Iemma, F.P. Nicoletta

Recent advances in the synthesis and biomedical applications of nanocomposite hydrogels

Pharmaceutics, 7 (2015), pp. 413-437 
28) J.L. Koening, A.C. Angood

Raman spectra if poly(ethylene glycols) in solution

J. Polym. Sci., 8 (1970), pp. 1787-1796

29) L. Song, Z.-I. Zhi, J.C. Picku

Nanolayer encapsulation of insulin-chitosan complexes improves efficiency of oral insulin delivery

Int. J. Nanomedicine, 9 (2014), pp. 2127-2136

30) J. Suckale, M. Solimena

Pancreas islets in metabolic signaling-focus on the beta-cell

Front. Biosci., 13 (2008), p. 7156

31) K. Guth, M. Schäfer-Korting, E. Fabian, R. Landsiedel, B. van Ravenzwaay

Suitability of skin integrity tests for dermal absorption studies in vitro

Toxicology, 29 (2015), pp. 113-123

32) S.N. Andrews, E. Jeong, M.R. Prausnitz

Transdermal delivery of molecules is limited by full epidermis, not just stratum corneum

Pharm. Res., 30 (2013), pp. 1099-1109 